\title{
O conceito de conflito nos estudos sociolinguísticos, interacionais e narrativos: Uma revisão epistemológica e teórico-analítica
} Glauber de Souza Lemos

Pontifícia Universidade Católica do Rio de Janeiro, Rio de Janeiro, RJ, Brasil

Revisitaremos a definição de conflito nos estudos da antropologia, da antropologia linguística, da sociolinguística, da sociolinguística interacional e da fala-em-interação. Exploraremos, também, como as comunidades linguísticas são vigiadas e reguladas pelas ideologias e prescrições linguísticas, eclodindo conflitos linguísticos. Serão abordados, ainda, como ocorrem situações de conflito em interações da vida social e, depois disso, podendo ser rememoradas e narradas, apontando, assim, a perspectiva êmica e elencando as agendas dos interactantes e dos narradores. Este artigo apresenta contribuições acadêmicas, em âmbito microinteracional e em âmbito macrossocial, com foco nos estudos e análises de conflito, em processos comunicativos da fala-em-interação e das narrativas de conflito coconstruídas.

Palavras-chave: conflito, conflito linguístico, fala de conflito, narrativas de conflito, microconflito interacional
The Concept of Conflict in Sociolinguistic, Interactional and Narrative Studies: An Epistemological and Theoretical-Analytical Review revisits the definition of conflict in the studies of anthropology, linguistic anthropology, sociolinguistics, interactional sociolinguistics, and talk-in-interaction. We will also explore how linguistic communities are monitored and regulated by linguistic ideologies and prescriptions, resulting in linguistic conflicts. We will also discuss how conflict situations occur in social life interactions and, after that, they can be recalled and narrated, thus pointing to emic perspective and listing agendas of interactants and narrators. This article presents academic contributions, at microinterational and macro-social levels, with a focus on studies and conflict analysis, in communicative processes of talk-ininteraction and co-constructed conflict narratives.

Keywords: conflict, linguistic conflict, conflict talk, conflict narratives, interactional microconflict

\section{Introdução}

A contemporaneidade está repleta de diversidade linguística e de novas formas de comunicação, podendo ser multimodal e translíngue. Mas nem sempre houve/há aceitabilidade em abarcar as várias formas comunicativo-linguísticas e, muito menos, houve/há as pacificações nos intergrupos e nas comunidades linguísticas. Exemplo disso são as interações conflitivas tanto interpessoais quanto linguísticas, entre os séculos XVI a XXI, em contexto nacional e internacional.

No século XVI, por exemplo, os portugueses se depararam com um território, que chamariam de "brasileiro", plurilíngue e com diversos dialetos e línguas-em-uso, em situações de contato linguístico, entre os povos tradicionais potiguaras, tupinambás, tabajaras, tupiniquins, caetés e tamoios. Nesse período, os portugueses colonizadores objetivavam dominar os territórios dos povos tradicionais e, para isso, implementaram e empreitaram um projeto de base ideológica católica. $\mathrm{Na}$ 
historiografia da educação brasileira, registra-se que, em 1534, foi criada a principal ordem religiosa, a Companhia de Jesus (SAVIANI, 2008, p. 149). Os "soldados de Cristo", oriundos de colégios jesuítas, aprenderam a língua tupi, mas com o foco missionário-pedagógico (ARANHA, 2006, p. 272). O objetivo dos jesuítas era ensinar os povos tradicionais a ler e a escrever as línguas portuguesa, espanhola e latina (SILVA-REIS e MILTON, 2016, p. 2), para, assim, colonizarem, explorarem e povoarem as terras "brasileiras". Nesse período, os conflitos se intensificaram e os povos tupi-guarani e tapuias resistiram e lutaram contra o projeto de homogeneização religiosa, identitária e linguística. Essa parte da história brasileira registra-se com conflitos linguístico, religioso e interétnico.

Outro exemplo são os estudos analíticos sobre os processos comunicativos e linguísticos conflitivos (microconflitos, escalonamento do conflito e agravamento do conflito), em interações face a face, entre os séculos XX e XXI. As análises de situações naturalísticas (ou seja, as situações vivenciadas na vida cotidiana) de conflito buscam identificar os microconflitos: alguns podem ser resolvidos rapidamente (por exemplo, quando um casal gerencia as "brigas" de seus filhos com extrema urgência e se esforçam para diminuir ou dirimir o conflito interpessoal); outros podem ser mantidos por um longo tempo (por exemplo, quando uma esposa gerencia um conflito familiar de longo prazo entre seu marido e sua sogra); outros ainda podem ser escalonados episodicamente (por exemplo, quando um marido, em um período "sentimental patriótico" de sua vida, se alista voluntariamente ao exército para participar de um conflito militar em outro país) (GARVEY e SHANTZ, 1995[1992], p. 22).

Neste artigo, veremos que o estudo e a análise do conflito linguístico, em âmbito macrossociológico e sociolinguístico, está presente em comunidades linguísticas (majoritárias ou minoritárias) e com variantes linguísticas de estilo (em perspectiva da socioestilística). Nesse sentido, analisa-se o posicionamento político e institucional, o preconceito linguístico, as ideologias discursivas, as prescrições linguísticas e as autorregulações de normas/padronizações linguísticas. Já em âmbito microssociológico, microinteracional e sociolinguístico, os estudos e as análises de conflitos centramse nas interações conflitivas de fala de conflito (em interações naturalísticas e de face a face) e de narrativas de conflito (depreendendo a rememorização e a lembrança de histórias de conflito e com micro eventos-de-conflito), mas que causam/causaram um impacto no ecossistema comunicativo.

O objetivo deste artigo consiste em apresentar alguns conceitos de conflito e estabelecer relações interdisciplinares sobre as teorias do conflito. A perspectiva teórica está alinhada aos estudos de conflito na antropologia (CARDOSO DE OLIVEIRA, 2008), na antropologia linguística (JACQUEMET, 2000), na sociolinguística (BAGNO, 1999, 2017; LAGARES, 2011, 2018), na sociolinguística interacional (GRIMSHAW, 1990) e na fala-em-interação (GRIMSHAW, 1990; SILVEIRA e MAGALHÃES, 2008). Buscarei, ainda, conceituar o conflito linguístico (WEINREICH, 1953; NINYOLES, 1989; MCRAE, 1983; NELDE, 1987; POSNER, 1993; LAGARES, 2011, 2018), a fala de conflito (EISENBERG e GARVEY, 1981; MAYNARD, 1985; GRIMSHAW, 1990; 
VUCHINICH, 1990; GARCIA, 1991; GRUBER, 1998; LEUNG, 2002; STERWART e MAXWELL, 2010; NGUYEN, 2011) e a narrativa de conflito (BRIGGS, 1996; BRENNIES, 1996; LEMOS, 2019).

A seguir, revisitarei a definição de conflito social e de conflito nas relações humanas. Em seguida, abordarei o conceito de conflito linguístico relacionado às ideologias linguísticas e à prescrição da/na linguagem. Depois, discutirei a concepção de fala de conflito e de narrativa de conflito. Por fim, apresentarei as considerações finais.

\section{As noções conceituais e epistemológicas sobre conflito}

As manifestações de conflito podem ser de ordem histórica, social, econômica, religiosa, étnica, cultural, identitária e linguística. Giddens e Sutton (2016, p. 311) definem conflito como um processo de "luta entre grupos sociais, envolvendo tensões, discórdia e choque de interesses". Posner (1993, p. 41), por sua vez, aponta que o conflito foi compreendido, em perspectivas marxista e weberiana, como uma "competição entre classes sociais para obter o poder" e que, muitas vezes, o "conflito social" pode ser intensificado pela linguagem, pelo trabalho e pelas diferenças de crenças políticas e religiosas.

A partir da perspectiva sociológica (ou das "sociologias do conflito") de Giddens e Sutton (2016), tratarei o conceito de conflito em duas ordens: macro e microssociológica. $\mathrm{Na}$ ordem macrossociológica, o conflito precisa ser analisado por uma lente de fatos históricos e razões históricas

- por exemplo, em expansões territoriais com colonialismo, exploração de populações e guerrilhas territoriais, eclodindo em violências e rivalidades. Em contrapartida, na ordem microssociológica, o conflito é observado em interações e no contato de pessoas em interações sociais (GIDDENS e SUTTON, 2016, p. 314). Há ainda, a concepção de conflito decorrente da convivência social do ser humano, a partir de suas próprias contradições (inter)subjetivas.

Na perspectiva antropológica, o antropólogo Cardoso de Oliveira (2008), em "Existe violência sem agressão moral?", investiga dados de conflitos que envolvem afirmações de direitos e demandas de pedidos de reconhecimentos, em eventos judiciais (juizados criminais), analisando contextos etnográficos no Brasil, no Canadá e nos Estados Unidos da América (EUA). O autor reflete sobre o "insulto moral", centrando-se nos ressentimentos das vítimas atingidas pelo conflito e conceituando-o em dois fenômenos: “(1) trata-se de uma agressão objetiva a direitos que não pode ser adequadamente traduzida em evidências materiais; e (2) sempre implica uma desvalorização ou negação da identidade do outro" (CARDOSO DE OLIVEIRA, 2008, p. 136). Para Cardoso de Oliveira, a dicotomia entre "consideração" e "desconsideração" (conceitos cunhados em Hegel, Taylor e Rousseau) ocasiona agravamentos dos conflitos na linguagem e no discurso das/nas interações sociais, por conta da falta de reconhecimento, (de)consideração e reciprocidade. Essas 
“experiências de ressentimentos" são causadas quando há "negação da identidade do interlocutor", fazendo-o sentir-se agredido e, assim, caracterizando o "lugar dos sentimentos na percepção do insulto", sendo provocado pela indignação moral (Ibid., pp. 136-137).

Nessa mesma linha antropológica, Montanari (2013, p. 93) concebe o conflito como uma forma de relação e interação entre os sujeitos (tanto individual quanto coletivo) que pode ser desencadeada pela frustração ou pelo anseio "por reconhecimento", mas interligado à defesa do papel social e das identidades (MONTANARI, 2013, p. 96). Montanari argumenta que a simples imaginação de que o outro possa impedir uma ação do $e u$, certamente pode interferir na relação entre duas ou mais pessoas em interação. $\mathrm{O}$ autor se refere aos estudos de interações conflituosas, quando há tentativas de localização das funções de "terceiros" na "situacionalidade de conflito" (Ibid.).

$\mathrm{Na}$ perspectiva da antropologia linguística, Jacquemet (2000) define o conflito em ordem macro e micro, assim como Giddens e Sutton (2016). Jacquemet defende que o conflito permite a compreensão da intercessão entre linguagem (na ordem sociolinguística interacional e analítica da conversa) e poder (na ordem filosófico-sociológica, com contribuições teóricas de Foucault e Bourdieu). Isso porque, em muitos momentos da vida, o conflito pode romper os laços sociais e provocar colapsos sociais - por exemplo, confrontos territoriais/interétnicos e disputas familiares ou interpessoais (JACQUEMET, 2000, p. 42). Muitas vezes, o conflito precisa ser administrado pela comunicação, com redes interacionais e, algumas vezes, com mediadores de conflito, para que se possa reconfigurar a ordem interacional. Jacquemet notifica que o conflito é constituído de acusações e solicitações, exigindo as responsabilidades dos acusados, mas sempre apresenta os anseios dos avaliadores do conflito. $\mathrm{O}$ autor aponta, ainda, que por meio de análises (dos pisos) interacionais e de seus respectivos dispositivos discursivo-linguísticos é possível observar como em uma conversa entre pessoas há repentinos conflitos e, consequentemente, "colapsos na coerência conversacional”, gerando assimetrias e "dominação interacional” (Ibid.).

Por fim, na perspectiva da sociolinguística, o conflito é interpretado "como uma atividade social, criado e conduzido, principalmente, por meio da fala" e em processos interativos da vida cotidiana (GARVEY e SHANTZ, 1995[1992], pp. 93-94).

Assim, compreendo o conflito como um processo social (GRIMSHAW, 1990, p. 1) e um ato de fala, ou seja, uma ação social e uma prática comunicativa e linguística, presente tanto em situações nucleares quanto em situações periféricas, com "efeitos sociais e políticos em diferentes contextos institucionais e ideológicos" (JACQUEMET, 2000, pp. 42, 44). Em momentos interacionais com usos de linguagens, o conflito altera os repertórios dos significados sociais, as ideologias linguísticas (por exemplo, as autorregulações de normas/padronizações e as higienizações/prescrições linguísticas) e as relações de poder, transformando as relações sociais e as estruturas sociais.

Em seguida, apresentarei o conceito de conflito linguístico na perspectiva sociolinguística. 


\section{Conflito linguístico: ideologias linguísticas e prescrição da/na linguagem}

Cotidianamente, as línguas e as linguagens são vigiadas, reguladas, prescritas e normatizadas (CAMERON, 1995; BAGNO, 1999; LEMOS, 2019). No entanto, a padronização linguística, em comunidades linguísticas minoritárias, conforme Lagares (2018), pode sofrer situações de desigualdade linguística e conflitos linguísticos, sendo ocasionadas pela violência simbólica ${ }^{1}$ (BOURDIEU, 1989, 2012[1998]) e pelas ideologias linguísticas² (CAMERON, 2006).

Segundo Nelde (1987), o contato entre diferentes idiomas implica conflitos. Para Posner (1993, p. 42), por sua vez, o conflito linguístico é ocasionado quando duas (ou mais) línguas são sobrepostas, causando, assim, disputas hierárquicas e de poder entre as línguas. Ninyoles (1989 apud LAGARES, 2018, p. 132) cunhou o conceito de conflito linguístico como "um 'desajuste' entre as funções sociais da linguagem e as funções linguísticas da sociedade, em situações de línguas em contato".

Lagares (2018) destaca que o ponto chave da noção de conflito linguístico "seria a impossibilidade de encontrar algum equilíbrio ou estabilidade quando há línguas em situação de desigualdade social" (p. 132). Por exemplo, um conflito linguístico pode ser iniciado quando um falante bilíngue se defronta com a lealdade e a deslealdade entre dois idiomas, ocasionando o primeiro tipo de conflito (POSNER, 1993, p. 42). Outro exemplo é apresentado por Lagares (2018), quando aponta que o conflito linguístico é tomado de situação política (linguística), hierárquica e desigual entre as línguas, alocando-as entre língua majoritária versus língua minoritária. Há ainda outro exemplo de conflito linguístico, quando em comunidades linguísticas, as suas respectivas línguas estão em contato (WEINREICH, 1953), mas há perseguição e intolerância linguística, fomentando, assim, o ressentimento entre os grupos (POSNER, 1993, p. 42).

Ainda segundo Lagares (2011), as situações de contato linguístico e de diglossia com e sem bilinguismo podem provocar o conflito:

\footnotetext{
A ideia de conflito remete a visão mais dinâmica e pode comtemplar todo tipo de situações em que se produza um enfrentamento entre grupos ou forças. E os conflitos linguísticos (...) quer entre o que são consideradas variedades de uma mesma língua, quer entre línguas reconhecidamente diferentes (e, sobretudo, nos muitos casos em que essas distinções não estão claras), trazem para a cena de forma inevitável a questão da norma linguística (LAGARES, 2011, p. 174).
}

McRae (1983) apresenta quatro estruturas chave em que se eclode o conflito linguístico: 1) a evolução histórica da diversidade linguística; 2) a estrutura social das comunidades linguísticas e seus respectivos vínculos com outras divisões sociais; 3) as atitudes e as mobilizações das comunidades linguísticas; e 4) os arranjos institucionais e constitucionais organizados pelos grupos linguísticos, em setores públicos e privados. Já Lagares (2018, pp. 134-136), ao revisitar a obra de Ninyoles (1989, pp. 
61-87), Estrutura social e política linguística, destacam-se os principais fatores sociais que causam os conflitos linguísticos, em sociedades industriais e urbanas, sendo subdividas/organizadas em quatro esferas: 1) governamental (há escolha de uma língua a ser utilizada nas funções políticoadministrativas estatais); 2) educacional (decide-se pela língua de instrução dentre tantas outras línguas faladas no território); 3) religiosa (há convecção de uma língua sagrada e de uma língua comum para todos); e 4) trabalhista (exige-se a competência linguística de uma língua hegemônica/dominante, promovendo a desigualdade linguística e a desvantagem trabalhista).

Pastor e De Fina (2005, p. 36), em Costesting Social Place: Narratives of Language Conflict, observam as narrativas de conflitos linguísticos de mulheres mexicanas que tiveram experiência de migração para os EUA, precisamente, em San Diego, na Califórnia. Por conta da falta de proficiência linguística, essas mulheres enfrentaram dificuldades em instituições públicas e privadas, recebendo constantemente tratamento hostil. As narrativas apresentam como as relações de poder e as hegemonias sociais atuam sobre os migrantes, que, por serem falantes de espanhol, sentem-se alocados em uma posição inferior (pertencentes ao grupo social minoritário) diante dos falantes nativos de inglês (pertencentes ao grupo social dominante e majoritário). Os autores tratam da discussão sobre a "diversidade linguística", que consiste em permitir a circulação de várias línguas em um território social, mas quando essa diversidade linguística é colocada em xeque dá-se lugar ao monolinguismo e ao preconceito linguístico. Os autores exemplificam duas situações de conflito linguístico que tiveram lugar na Califórnia: primeiro, quando ocorreu a expansão de grupos xenofóbicos e se incluiu em seus projetos a promulgação do inglês como a única língua oficial do estado; segundo, quando se inseriu outro projeto destinado à eliminação da educação bilíngue nas escolas (PASTOR e DE FINA, 2005, p. 39).

Posner (1993) notifica que quando uma comunidade bilíngue trata um idioma como superior e outro como inferior eclodem tensões e conflitos linguísticos. A disputa social, a repressão política e a desaprovação social impõem desigualdades e sobreposições linguísticas, apontando divergências de interesses e de valores entre os diferentes grupos (POSNER, 1993, p. 42; BAGNO, 2017, pp. 5455). Um exemplo disso foram as ideologias nazista (alemã) e fascista (italiana), ambas declaradamente contrárias ao bilinguismo, que promulgavam que os sujeitos bilíngues eram "desleais, instáveis e intelectualmente atrasados", além disso, promoveram um plano linguísticonacionalista (centrado na homogeneidade da linguagem/homogeneidade linguística) de circunscrição/circulação de apenas uma "língua nacional", com o intuito de suprimir as línguas e os dialetos das minorias linguísticas (WEINREICH, 1953, pp. 117-120; POSNER, 1993, p. 43).

A desigualdade de poder entre as línguas caracteriza um "conflito diglóssico" (FISHMAN, 1967; LAGARES, 2011, 2018), ou seja, uma relação assimétrica e não estável entre as línguas, tensionando as interações sociais e promovendo o "jogo de ocupação linguística" (MAHER, 1997). Essas 
assimetrias linguísticas e conflitivas em comunidades, contextos e situações sociolinguísticas complexas (LEMOS, 2019) tendem a se formar por conta de: um grupo linguístico socialmente dominante; a ocorrência de agrupamentos espaciais homogêneos; o domínio social com um número de falantes e estratificação social e política das línguas dos grupos em contato; e as especificações funcionais e estratificações entre as línguas (NELDE, LABRIE, WILLIAMS, 1992, p. 390).

As interações face a face podem incluir conflitos na fala, como veremos a seguir, na revisão de literatura dos estudos sociolinguísticos interacionais e dos estudos da fala-em-interação.

\section{A fala de conflito em estudos da fala-em-interação}

Os estudos de conflito têm sido realizados interdisciplinarmente, em campos como a filosofia, psicanálise, antropologia, sociologia, psicologia, linguística e os estudos da linguagem. Interações sociais com relações de conflito têm sido estudadas e analisadas em encontros cotidianos, situações institucionais e contextos educacionais, legais, médicos, além de interações na família ou em grupos (ver LEMOS, 2019).

O antropólogo e sociolinguista Grimshaw (1990, p. 1), em Conflict Talk ${ }^{3}$, comenta que o conflito está presente na vida social humana. No livro, Grimshaw introduz questões metodológicas e analíticas importantes sobre o conflito, tais como: quais são os locais, os grupos e as situações sociais em que emergem as falas de conflito; por que motivos e temáticas se iniciam os conflitos entre as pessoas; como se decifra o início, o meio e o fim de um conflito na fala-em-interação; e quais são os participantes de interações de conflito. Grimshaw denota que os conflitos podem acontecer em qualquer ambiente social, por exemplo: em uma creche, entre crianças; em uma escola, no refeitório em momento de recreio ou em sala de aula; em um ambiente familiar, na sala de estar; em uma empresa, com desentendimento entre chefe e funcionários. Ou seja, em todos os ambientes com interações da vida social cotidiana pode iniciar conflitos na fala-em-interação. Os métodos de estudo e análise são variados, incluindo gravações em áudio e em vídeo, mas sempre com materiais etnográficos e transcrições finas das falas (GRIMSHAW, 1990, p. 2). Na dimensão sociológica do conflito, o autor apresenta os "jogos de disputas" como momentos que rementem à briga entre duas ou mais pessoas, com estabelecimento e/ou reafirmação da estrutura social, além de conduzirem às situações de negociações e de reivindicações. $\mathrm{Na}$ área da linguística, o autor aponta as "situações de conflito", com diferentes relações de poder, afeto e falta de reconhecimento (Ibid., p. 3).

Leung $(2002$, pp. 1,3) retrata que a análise da fala de conflito investiga o percurso interacional do conflito, analisando o início e o término de tópicos/turnos interacionais e linguísticos com conflitos. Leung (Ibid., pp. 6, 10-11) salienta que, uma vez iniciado um episódio de conflito, a sua 
trajetória na conversa pode ser desconcertante, perpassando pela agressividade verbal, pelo escalonamento do conflito e pelo clímax do conflito. Nguyen (2011, p. 1755), por sua vez, salienta que a chave da determinante da identificação de um dado com fala de conflito está na observação da sequência (ou seja, na sequencialidade do conflito) de dois ou mais turnos interacionais, isto significa que é preciso analisar a "virada oposicionista" do escalonamento do conflito (LEUNG, 2002). Assim sendo, um único turno de oposição, não se constitui como uma fala de conflito. Por isso, é preciso analisar, microanaliticamente, momento por momento da interação de conflito, para, assim, identificar o início, o escalonamento e o possível fim do conflito.

Sterwart e Maxwell (2010, p. 19) compreendem, assim como Maynard (1985), que um "episódio de conflito" pode ser estabelecido por uma simples declaração de um falante a outro, causando "sequências de contradeclarações". Eisenberg e Garvey (1981, p. 150) afirmam que "um episódio adverso é uma sequência que começa com uma oposição" e termina com a "resolução do conflito" ou "dissipação do conflito". Todavia, uma vez que se estabelece um "episódio de conflito", esse fenômeno continua até a fase seguinte, podendo ser mais longo o período de dissipação e perdurando até que alguns dos participantes declarem as suas visões opostas ou esclareçam as suas perspectivas sobre o assunto causador do conflito (GRUBER, 1998).

As interações familiares com conflitos verbais e desacordos foram observadas por Vuchinich (1990), em The Sequential Organization of Closing in Verbal Family Conflict. O autor conceitua o "conflito verbal" como uma atividade de fala, podendo incluir dois ou mais participantes em um ato de interação. No ambiente familiar, o terceiro participante pode ser o causador do conflito - por exemplo, um dos pais (VUCHINICH, 1990, p. 120). Nos relacionamentos com conflito que não chegam a uma conclusão, pode-se utilizar a estratégia interacional de stand-off ${ }^{4}$ como uma maneira de ninguém "perder a face" (GOFFMAN, 2012[1967]), sem exigência de compromisso, submissão ou ato de concessão, tornando o caminho mais fácil para pôr fim ao conflito (VUCHINICH, 1990, p. 134). O autor observa, a partir de seus dados, a recorrência de cinco formatos do "encerramento de conflito" em contexto familiar: 1) a "submissão" (assentimento do oponente), quando uma parte aceita a posição da outra parte; 2) o "compromisso", quando uma concessão é oferecida por uma parte e aceita por outra; 3) o standoff, quando nenhuma submissão ou compromisso é alcançada, com turnos e falas seguidas de silêncio; 4) a "retirada", quando um dos oponentes da conversa de conflito se retira da atividade da fala ou do ambiente físico em que conversavam; e 5) a "intervenção de terceiros" (facilitador/mediador), quando um terceiro participante neutro, com mais autoridade que os oponentes do conflito, emite uma opinião para encerrar a disputa. Pode ser, ainda, que os oponentes se submetam ao terceiro, sem desejar ganhar a face para o seu lado e sem pedir a opinião, mas permanecendo em oposição entre si (Ibid., pp. 123-134). 
Na perspectiva da análise da conversa etnometodológica (ACE), Garcia (1991, p. 821) estuda os conflitos nas acusações, em contextos de audiências, com mediação do conflito. O estudo é centrado na mudança da estrutura de participação na fala-em-interação entre os disputantes. A autora analisa as recorrências de categorias do/no conflito, como "recusas", "reparos", "preferências" e "despreferências", além da sequência da interação com "tomadas de turnos". Ela observa que, se os disputantes não podiam interromper uns aos outros durante suas histórias de reclamação, em contrapartida, os mediadores do conflito interrompiam a interação para fazer perguntas e/ou reorientar a história para um tópico específico. Além disso, um "episódio de conflito" levava às contra-acusações, ou contra-afirmações, ou negações, sendo estas produzidas pelos acusadores com "reparo" e "mitigação das acusações" (GARCIA, 1991, pp. 821-822).

Nessa mesma linha de pesquisa, Silveira e Magalhães (2008), em A fala-em-interação em situações de conflito: Recursos linguísticos e práticas comunicativas, analisam dados gerados no âmbito do Programa de Proteção e Defesa do Consumidor (Procon), centrando-se na interação social e na ação social de atores sociais, na interface interacional/institucional e na relação linguagemtrabalho (contexto profissional). Na apresentação da obra, as autoras situam os artigos em que os pesquisadores apresentam dados de participantes que se engajam em atividades verbais e não-verbais na construção/negociação de identidades, em relações de conflito mediadas, com emprego de recursos linguístico-discursivos, de acordo com os pressupostos teóricos de cada pesquisa (SILVEIRA e MAGALHÃES, 2008, pp. 7-10). Os pressupostos teóricos e as categorias analíticas são: 1) da sociolinguística interacional, com a aplicação de conceitos de "pistas de contextualização", "enquadres", "alinhamentos", "arranjos interacionais", "estrutura de participação", "self" e "face”; 2) da análise da conversa, mediante a análise de ações interacionais, com "categorizações", "alocação de turnos", "troca de turnos", "reparo" e "mediação"; 3) da teoria do posicionamento, centrada em "posicionamentos interacionais"; 4) da análise da narrativa, com estudo interacional de "narrativas", "relatos", e "avaliações"; e 5) da argumentação de ordem micro, com análise de "formulações" e "estratégias argumentativas" no curso da interação ou de relações de "evidencialidade" e "causalidade".

A seguir, apresentarei as narrativas de conflito, com a fundamentação teórica dos estudos sociolinguísticos interacionais.

\section{Narrativa de conflito: memória de histórias de conflito}

A intersecção entre narrativa e conflito encontra-se na obra organizada por Briggs (1996), em Disorderly Discourse: Narrative, Conflict, and Inequality. Na introdução, o autor discute as contribuições de ordem teórico-metodológica, revisitando autores que estudam as narrativas de 
conflito (BRIGGS, 1996, pp. 3-4). Briggs apresenta que o conflito é uma "característica comum da vida social" e uma "sobrevivência da coletividade", tomando como ponto de partida as construções de identidades e as identificações dos processos de diferenciações entre o "eu" e o "outro" nas relações sociais. Briggs retoma, ainda, o conceito de conflito em Foucault e em Bourdieu, pois ambos os autores relacionam as questões de poder e de conflito nas relações humanas. Entende, também, que as narrativas são formas de se construir experiências pessoais, podendo ser coconstruídas.

Briggs (Ibid., p. 10) sustenta que as narrativas de conflito fornecem reflexões sobre as identidades individuais, com perspectiva êmica a fim de elencar as agendas dos narradores. Como, então, analisar o conflito em narrativas? O autor salienta que é preciso: 1) observar a narrativa como um evento passado (pp. 5, 14); 2) incluir uma análise sobre as relações indexicais e iconográficas, as seleções lexicais/contextuais e as relações entre os participantes narrados na história (p. 15); 3) analisar a narrativa como prática metadiscursiva e metapragmática (pp. 19, 22-24); e 4) explorar como os narradores assumem a agência e os papéis dos personagens na narrativa (p. 26).

Outra contribuição sobre as narrativas de conflito é a de Brennies (1996), em Telling Troubles: Narrative, Conflict, and Experience. O autor lança um olhar sobre os conceitos de "narrativa", "história", "evento" e "conflito", entendendo que "os vários papéis da narrativa auxiliam o gerenciamento dos conflitos sociais" (BRENNIES, 1996, p. 42). Brenneis indica que o "conflito é um processo e não um estado", ou seja, as narrativas se compõem com "inícios, meios e, ocasionalmente, fim", com objetivo de conduzir "a disputa a um fim" (Ibid., p. 43). Suas pesquisas geraram dados etnográficos no Nepal, em "Fiji de Bhadgaon", onde ele observou como os membros da comunidade contavam as histórias de fofoca - "eventos sobre fofocas" ou "sessões de fofocas" na aldeia. O autor analisa que uma disputa e uma narrativa "assumem um papel de autoridade" - nas sessões de fofocas na aldeia Bhadgaon, quando as histórias dos outros eram rejeitadas, ou ainda, simplesmente não eram ouvidas, configurando tomadas autoritárias de poder - e de "multivozes". Nessa aldeia, os "eventos narrativos" ${ }^{5}$ de conflitos incitavam reações em outros membros da comunidade, principalmente quando ouviam as narrativas apresentadas por um narrador, fomentando-se réplicas e relatos contrários ao que foi narrado (Idem).

Brenneis explora, ainda, a eficácia dos "eventos narrativos" e como eles se engendram com as experiências pessoais da/na realidade social. $\mathrm{O}$ autor aponta que as narrativas de conflito estão relacionadas aos "eventos", às situações específicas em que são contadas e às circunstâncias particulares (a audiência, os propósitos e as expectativas) do narrador (Ibid., pp. 43, 50). Assim, defrontamo-nos com a seguinte questão levantada por Brenneis sobre essas narrativas de conflito: "de quem é essa história e quem tem o direito de contá-la?". Assim, reflete que as narrativas de conflito "são eficazes em moldar tanto o curso futuro do conflito quanto os contornos da vida social" e, ainda, que "essas histórias ajudam os participantes a definir, a esclarecer e a compreender os relacionamentos 
problemáticos e eventos preocupantes" (Ibid., pp. 47-48) sobre as instituições e sobre as comunidades complexas. Com essa reflexão, o autor aponta que a narrativa transforma a experiência social, pois "contar uma história é uma atividade inerentemente social" (Ibid., p. 49).

Já com o foco mais específico na "coconstrução de narrativas de litígio", em interações de conflitos interpessoais, Stewart e Maxwell (2010) trazem grande contribuição com a obra Storied Conflit Talk. As autoras analisam os "episódios de conflito" na coconstrução de narrativas de disputa, internacionalmente coconstruídas pelos participantes. Citando Brenneis (1996, p. 42), as autoras destacam que os "eventos narrativos em um episódio de conflito engendram e transformam a experiência social". Nesse caso, comentam que, em um "episódio de conflito", os participantes apresentam diferentes perspectivas e interpretações dos eventos de acordo com os seus interesses (STEWART e MAXWELL, 2010, p. 4). Os "conflitos insanáveis", ou seja, as situações de conflito sem resolução, podem ser destrutivas, gerando, assim, medo, raiva e culpa, além de causar danos emocionais e físicos (Ibid., p. 15).

Assim sendo, é preciso observar como, nas narrativas de conflito, os falantes narram acusamentos e negociações, bem como suas defesas e justificativas, e quais são os papéis dos personagens narrados na história contada - se estão em concorrência ou em disputa (BRIGGS, 1996; BRENNEIS, 1996; STEWART e MAXWELL, 2010). Esses mecanismos analíticos possibilitam não apenas examinar os eventos narrados com conflitos, mas também compreender os contextos circundantes no ato da interação do conflito (STEWART e MAXWELL, 2010, p. 12).

Seguindo essas premissas teóricas, metodológicas e analíticas - a partir da antropologia linguística, da sociolinguística interacional e da fala-em-interação -, Lemos (2019) também observa as narrativas de conflito. Os dados de sua pesquisa foram gerados em entrevistas, com sujeitos surdos sinalizantes da Língua Brasileira de Sinais (Libras) e profissionais Tradutores-Intérpretes de Libras/Português (TILSP). A partir da perspectiva da textualização narrativa de Labov e Waletzky (1967), o autor analisa os eventos de histórias de conflitos, compreendendo que são histórias constituídas por elementos que traçam sequencialidades da narrativa de conflito e avaliações dos eventos de conflito. Lemos (2019) reconstitui e reaplica os mecanismos analíticos de Briggs (1996) e de Brennies (1996), observando os usos discursivos de dêiticos (são elementos estruturais linguísticos que expressam apontamentos e indicações de referência ao lugar, ao tempo, ao contexto) e de indexicalidade (são significados sociais, pistas interpretativas e indicações de atribuições da identidade de si ou do outro, tornando relevantes no discurso as características contextuais) para apontar e indicar os agentes-causadores e os agentes-vítimas da narrativa de conflito relatada pelos participantes da pesquisa. Além disso, o autor analisa, microscopicamente, como os narradores reconstroem as vozes do eue do outrodos personagens, a partir de diálogos construídos, com o intuito de analisar os momentos conflitivos e as construções identitárias de todos os componentes da história na narrativa de conflito. 


\section{Considerações finais}

O objetivo deste artigo foi apresentar os estudos de conflito, em interface com os estudos da antropologia, da antropologia linguística, da sociolinguística, da sociolinguística interacional e da fala-em-interação. Busquei expor o conceito de conflito em dois principais pilares de conhecimento: 1) em ordem sociológica, discutindo a luta social, as disputas e as tensões entre grupos sociais, com eclosões de macroconflitos territoriais, políticos e interétnicos; e 2) em ordem antropológica linguística e sociolinguística, apontando como os microconflitos linguísticos, as falas de conflito e as narrativas de conflito geram/geraram problemas comunicativos e interacionais.

Nos estudos sociolinguísticos, os conflitos linguísticos são analisados pelos entrecruzamentos de posições ideológico-linguísticas, de disparidades socioeconômicas e linguísticas, de particularismo cultural e religioso e de comportamento competitivo linguístico, principalmente referente às sobreposições/desigualdades linguísticas e às normatizações/prescrições da/na linguagem.

Vimos que os estudiosos do conflito, nas perspectivas da sociolinguística, da sociolinguística interacional e da fala-em-interação, analisam os dados de conflito de várias formas e aplicam diversas metodologias e categorias analíticas, observando as esferas sociais, as fases, as sequências e as microfalas interacionais dos conflitos.

Nos estudos de fala-em-interação, os pesquisadores observam a fala de conflito entre dois ou três participantes em processo interacional face a face, expondo as discordâncias, os desalinhamentos, as recusas, os reparos e as (des)preferências na sequência interacional das falas. Observam, ainda, os episódios de conflito, o escalonamento e o agravamento, analisando seu início, meio e fim, e mostrando que essas interações podem ter ou não a resolução/dissipação do conflito.

Por fim, nos estudos sociolinguísticos interacionais e narrativos, os estudiosos observam que as narrativas de conflito são contadas por indivíduos que relatam uma história de conflito, apresentando o(s) evento(s) de conflito e o seu ponto clímax. Há também, nessas histórias, um início, um meio e um fim (ocasionalmente solucionando ou não a história de conflito), tematizando, principalmente, as disputas, os sofrimentos, os processos de resistência, as queixas de estigmas impostos e de relações de poder assimétricas, além de apontarem como alguns personagens da narrativa podem causar uma situação de desconforto, medo e raiva.

Os estudos de conflito, na perspectiva sociolinguística, podem contribuir para o entendimento das interações sociais e apontar como algumas interações causam situações conflitivas na linguagem-em-uso. Os conflitos são atravessados pelas relações de poder e pelo ressentimento, mas causado pela desconsideração das identidades e das agendas das comunidades linguísticas sociolinguisticamente complexas. 
Portanto, considero que os estudos minuciosos e microscópicos de sequências e fases dos (micro)conflitos, sob uma perspectiva macrossociológica, microssociológica e sociolinguística, em comunidades linguísticas, possibilitam o entendimento e a identificação das disputas e de práticas que afetam uma dada ecologia interacional e complexa. As análises de conflitos em interações naturalísticas e em atos de recontar de histórias de conflito apontam as emergências, as inteligibilidades $\mathrm{e}$ as agendas de interactantes e dos narradores a partir de trocas comunicacionais que afetam/afetaram ou desconsideram/desconsideraram a interação, mas que ferem/feriram as interações na vida social.

\title{
Notas
}

\begin{abstract}
${ }^{1}$ A violência simbólica é uma "violência suave, insensível, invisível às suas próprias vítimas, que se exerce essencialmente pelas vias puramente simbólicas da comunicação e do conhecimento, ou, mais precisamente, do desconhecimento, do reconhecimento ou, em última instância, do sentimento" (BOURDIEU, 2012[1998], p. 7).
\end{abstract}

${ }^{2}$ A ideologia está inerente aos sujeitos sociais. A ideologia é "uma abordagem relativamente coesa, que evolui dinamicamente, em um conjunto de ideias ou de crenças coletivas; são expressas verbalmente ou de alguma outra forma, sendo semiótica, performativa, ritual, artística ou comportamental" (CAMERON, 2006, p. 142). Cameron define "ideologias linguísticas" como as ideias e crenças sobre "o que seriam" e "como deveriam funcionar" uma língua (ou as linguagens), ou ainda, "como as línguas são usadas e julgadas em um contexto social" em determinadas "comunidades linguísticas específicas" (Ibid., p. 143).

${ }^{3}$ A obra é de ordem interdisciplinar, com contribuição de antropólogos, advogados, linguistas, psicólogos e sociólogos.

${ }^{4}$ No sentido de se retrair ou de se reservar (silenciar) como evitação do agravamento do conflito.

${ }^{5}$ Brennies (1996, p. 42) cita Bauman (1986, p. 6) salientando a diferença entre "evento narrado" e "evento narrativo". O "evento narrado" diz respeito ao conteúdo proporcional narrado no mundo e contado na história, ou seja, é a memória e o registro de um testemunho ou uma experiência vivenciada em um passado. Já o "evento narrativo" é a narrativa que emerge ao ser contada para o outro, dando uma "dimensão do significado de uma história", ou seja, é o fenômeno performativo de ativação da memória e reconstrução de uma história, recriando a experiência passada para uma dada audiência e contexto. 


\section{Referências}

ARANHA, Maria Lucia de Arruda. História da educação e da pedagogia: Geral e Brasil. São Paulo: Moderna, 2006.

BAGNO, Marcos. Preconceito linguístico. São Paulo: Parábola Editorial, 2015[1999].

BAGNO, Marcos. Dicionário crítico de sociolinguística. São Paulo: Parábola Editorial, 2017.

BAUMAN, Richard. Story, Performance and Event: Contextual Studies of Oral Narrative. Nova York: Cambridge University Press, 1986.

BOURDIEU, Pierre. O poder simbólico. Rio de Janeiro: Bertrand Brasil, 1989.

BOURDIEU, Pierre. A dominação masculina. Rio de Janeiro: Bertrand Brasil, 2012[1998].

BRENNEIS, Donald. "Telling Troubles: Narrative, Conflict, and Experience”. In: Disorderly Discourse: Narrative, Conflict, and Inequality. Nova York: Oxford University Press, 1996, pp. 41-52.

BRIGGS, Charles Leslie. "Introduction". In: Disorderly Discourse: Narrative, Conflict, and Inequality. Nova York: Oxford University Press, 1996, pp. 03-40.

CAMERON, Deborah. Verbal Hygiene: The Politics of Language. Londres: Routledge, 1995.

CAMERON, Deborah. "Ideology and Language". Journal of Political Ideologies, vol. 11, n. 2 pp. 141-152, 2006.

CARDOSO DE OLIVEIRA, Luís Roberto. “Existe violência sem agressão moral?”. Revista Brasileira de Ciências Sociais, vol. 3, n. 67, pp. 135-146, 2008.

EISENBERG, Ann R.; GARVEY, Catherine. "Children's Use of Verbal Strategies in Resolving Conflicts”. Discourse Process, vol. 4, pp. 149-170, 1981.

FISHMAN, Joshua Aaron. "Bilingualism with and Without Diglossia, Diglossia with and Without Bilingualism”. Journal of Social Issues, vol. 23, pp. 29-38, 1967.

GARCIA, Angela. "Dispute Resolution without Disputing: How the Interactional Organization of Hearings Minimizes Argument”. American Sociological Review, vol. 56, n. 6, pp. 818-835, 1991.

GARVEY, Catherine; SHANTZ, Carolyn Uhlinger. "Conflict Talk: Approaches to Adversative Discourse”. In: SHANTZ, Carolyn Uhlinger; HARTUP, Williard W. (orgs). Conflict in Child and Adolescent Development: Cambridge Studies in Social and Emotional Development. Nova York: Cambridge University Press, 1995[1992], pp. 93-121.

GIDDENS, Anthony; SUTTON, Philip W. Conceitos essenciais da sociologia. São Paulo: Editora Unesp, 2016.

GOFFMAN, Erving. Ritual de Interação: Ensaios sobre o comportamento face a face. Petrópolis: Vozes, 2012[1967].

GRIMSHAW, Allen Day. Conflict Talk: Sociolinguistic Investigations of Arguments in Conversations. Cambridge: Cambridge University Press, 1990. 
GRUBER, Helmut. "Disagreeing: Sequential Placement and Internal Structure of Disagreements in Conflict Episodes”. Text, vol. 18, n. 1, pp. 467-504, 1998.

JACQUEMET, Marco. “Conflict”. Journal of Linguistic Anthropology, vol. 9, n. 1-2, pp. 42-45, 2000.

LABOV, William; WALETZKY, Joshua. "Narrative analysis: oral versions of personal experience". In: HELM, June (org). Essays on the Verbal and Visual Arts. Seattle: University of Washington Press, 1967, pp. 3-38.

LAGARES, Xoán Carlos. "Minorias linguísticas, políticas normativas e mercados: Uma reflexão a partir do galego". In: LAGARES, Xoán Carlos; BAGNO, Marcos. Políticas da norma e conflitos linguísticos. São Paulo: Parábola Editorial, 2011, pp. 169-192.

LAGARES, Xoán Carlos. Qual política linguística? Desafios glotopolíticos contemporâneos. São Paulo: Parábola, 2018.

LEMOS, Glauber de Souza. Narrativas de conflito com alunos surdos e intérpretes de Libras nas relações com a família, a escola e atividades profissionais. Dissertação (Mestrado em Letras/Estudos da Linguagem) - Pontifícia Universidade Católica do Rio de Janeiro, Rio de Janeiro, 2019.

LEUNG, Santoi. "Conflict Talk: A Discourse Analytical Perspective”. Working Papers in Tesol \& Applied Linguistics, vol. 2, n. 3, 2002.

MAHER, Terezinha de Jesus Machado. "O dizer do sujeito bilíngue: aportes da sociolinguística”. In: Anais do Seminário Desafios e Possibilidades na Educação Bilíngüe para Surdos. Rio de Janeiro: Ines/Littera Maciel, 1997.

MAYNARD, Douglas W. "How Children Start Arguments". Language in Society, vol. 14, pp. 129, 1985.

MCRAE, Kenneth Douglas. Conflict and Compromise in Multilingual Societies, vol. 2. Waterloo, ON: Wilfrid Laurier Press, 1983.

MONTANARI, Federico. “Abordagem sociossemiótica de conflito e guerra”. In: FULANETTI, Oriana N.; BUENO, Alexandre Marcelo (orgs). Linguagem e política: princípios teóricodiscursivos. São Paulo: Contexto, 2013, pp. 93-116.

NELDE, Peter Hans. "Language Contact Means Language Conflict". Journal of Multilingual and Multicultural Development, vol. 8, n. 1-2, pp. 33-42, 1987.

NELDE, Peter Hans; LABRIE, Normand; WILLIAMS, Colin H. “The Principles of Territoriality and Personality in the Solution of Linguistic Conflicts". Journal of Multilingual and Multicultural Development, vol. 13, n. 5, pp. 387-406, 1992.

NGUYEN, Hanh Thi. "Boundary and Alignment in Multiparty Conflict Talk". Journal of Pragmatics, vol. 43, pp. 1755-1771, 2011.

NINYOLES, Rafael Lluís. Estructura social e política linguística. Vigo: Edicións Ir Indo, 1989.

PASTOR, Ana María Relaño; DE FINA, Anna. "Contesting Social Place: Narratives of Language Conflict”. In: BAYNHAM, Mike; DE FINA, Anna (orgs). Dislocations/Relocations: Narratives of Displacement. Manchester: St. Jerome, 2005, pp. 36-60. 
POSNER, Rebecca. "Language Conflict in Romance: Decline, Death and Survival". In: POSNER, Rebecca; GREEN, John N. (orgs). Trends in Romance Linguistics and Philology. Volume 5: Bilingualism and Linguistic Conflict in Romance. Berlim/Nova York: Mouton de Gruyter, 1993, pp. 41-75.

SAVIANI, Dermeval. "História da educação no Brasil: Um balanço prévio e necessário". EccoS Revista Científica, vol. 10, pp. 147-167, 2008.

SILVA-REIS, Dennys; MILTON, John. "História da tradução no Brasil: percursos seculares". Translatio, n. 16, pp. 2-42, 2016

SILVEIRA; Sonia Bittencourt; MAGALHÃES, Tânia Guedes. "Apresentação”. In: SILVEIRA, Sonia Bittencourt; MAGALHÃES, Tânia Guedes (orgs). A fala-em-interação em situações de conflito. São Carlos: Claraluz, 2008, pp. 07-10.

STEWART, Katherine A.; MAXWELL, Madeline M. Storied Conflict Talk: Narrative Construction in Mediation. Amsterdã/Filadélfia: John Benjamins Publishing Company, 2010.

VUCHINICH, Samuel. "The Sequential Organization of Closing in Verbal Family Conflict". GRIMSHAW, Allen Day (orgs). Conflict talk: Sociolinguistic Investigations of Arguments in Conversations. Nova York: Cambridge University Press, 1990.

WEINREICH, Uriel. Languages in Contact: Findings and Problems. Nova York: Linguistic Circle of New York, 1953.

\begin{abstract}
GLAUBER DE SOUZA LEMOS (glauberslemos@gmail.com) é doutorando em letras/estudos da linguagem no Programa de Pós-Graduação de Estudos da Linguagem (PPGEL) da Pontifícia Universidade Católica do Rio de Janeiro (PUC-Rio, Brasil), mestre pelo mesmo programa, e tem graduação em letras/português-literaturas e em pedagogia pela Universidade Estácio de Sá (Unesa, Rio de Janeiro, Brasil). É Tradutor-Intérprete de Língua Brasileira de Sinais/Língua Portuguesa (TILSP) do Instituto Nacional de Educação de Surdos (Ines).
\end{abstract}

https://orcid.org/0000-0001-5907-1653

Recebido em: 25/02/2020

Aprovado em: 11/08/2020 